\title{
ANALISIS POSITIONING PELAKU USAHA TANAMAN HIAS DI KOTA MAKASSAR
}

\section{Riska Tiasmalomo, Didi Rukmana dan Mahyuddin}

Program Studi Agribisnis, Sekolah Pascasarjana, Departemen Sosial Ekonomi Pertanian dan Fakultas Pertanian, Universitas Hasanuddin, Makassar.

Email: riskatyas23@gmail.com,drukmana@unhas.ac.id dan mahyuddin@agri.unhas.ac.id

\section{Abstract}

For the most part ornamental plant businessmen in Makasar city not know positioning from their own business. The aim of this research is to identify the characteristics of farmers and ornamental plant farming in Makassar City and analyze positioning on each ornamental plant businessmen in Makasar city. The method of analysis is used in this research is descriptive analysis and competitive profile matrix analysis. The results showed that the general characteristics of ornamental plant farmers in Makassar were male, aged $\geq 41$ years old, number of family dependents as many as 3 people, high school education level, and income level of Rp. 4,000,000 - Rp.15,000,000. While the general characteristics of ornamental plant farming in Makassar City are most of the business locations are in Tamalate District, the area of business is $\geq 15 \mathrm{~m}^{2}$, the source of business capital comes from own capital, the market scale is limited to the local area, and the status of business ownership is its own. As for the analysis is competitive profile matrix analysis shows that highest positioning value consecutive be managed by respondent 18 (Yetty) with positioning value of 3,769; respondent 8 (Arianto) with positioning value of 3,678; and respondent 7 (Sultan) with positioning value of 3,621 .

Keywords: characteristic, positioning, businessmen, ornamental plant

\section{Abstrak}

Sebagian besar pelaku usaha tanaman hias di Kota Makassar tidak mengetahui positioning dari usaha mereka sendiri. Tujuan penelitian ini adalah untuk mengidentifikasi karakteristik petani dan usahatani tanaman hias di Kota Makassar dan untuk menganalisis positioning setiap pelaku usaha tanaman hias di Kota Makassar. Metode analisis yang digunakan dalam penelitian ini adalah analisis deskriptif dan analisis competitive profile matrix. Hasil penelitian menunjukkan bahwa karakteristik umum petani tanaman hias di Kota Makassar adalah berjenis kelamin laki-laki, berusia $\geq 41$ Tahun, jumlah tanggungan keluarga sebanyak 3 orang, tingkat pendidikan SMA, dan tingkat pendapatan Rp. 4.000.000Rp.15.000.000. Sedangkan karakteristik umum usahatani tanaman hias di Kota Makassar adalah lokasi usaha sebagian besar berada di Kecamatan Tamalate, luas lahan usaha $\geq 15 \mathrm{~m}^{2}$, sumber modal usaha dari modal sendiri, skala pasar hanya sebatas wilayah lokal, dan status kepemilikan usaha adalah milik sendiri. Adapun 
hasil analisis Competitive Profile Matrix yang menunjukkan bahwa nilai positioning tertinggi berturut-turut dikuasai oleh responden 18 (Yetty) dengan nilai positioning sebesar 3,769; responden 8 (Arianto) dengan nilai positioning sebesar 3,678; dan responden 7 (Sultan) dengan nilai positioning sebesar 3,621.

Kata Kunci: karakteristik, positioning, pelaku usaha, tanaman hias

\section{Pendahuluan}

Indonesia memiliki berbagai jenis tumbuhan yang banyak tersebar si seluruh penjuru dan ada sekitar 30.000 tumbuhan, diantaranya 7.000 memiliki khasiat sebagai obat, dan sebanyak 2.500 merupakan tanaman obat (Meisintya De Nanda, 2019).

Salah satu bagian dari hortikultura yang berpotensi untuk dikembangkan saat ini adalah tanaman hias. Daerah tropis Indonesia dikenal memiliki keaenakragaman hayati dan kekayaan bumi Indonesia mencakup 27.500 jenis tanaman hias atau $10 \%$ dari seluruh jenis tanaman hias di dunia (Shinta, 2019). Saat ini tanaman hias (florikultura) memperoleh posisi yang penting dan telah menjadi sektor ekonomi pada abad dua puluh ini. Peningkatan permintaan terhadap tanaman hias telah menjadi sektor yang mengarah kepada keuntungan dan hal ini akan terus berlanjut dalam pengembangan suatu negara (Çelik \& Arisoy, 2013). Tanaman hias di Indonesia saat ini sedang mengalami pertumbuhan yang ditandai dengan berkembangnya daerah sentra produksi tanaman hias di wilayah perkotaan, serta makin tumbuh dan berkembangnya unit usaha yang melibatkan baik petani maupun pengusaha. Tujuan utama pengembangan usaha florikultura di Indonesia yaitu untuk memenuhi permintaan pasar Nasional dan Internasional. Oleh karena itu, pengembangan usaha florikultura harus dilaksanakan secara komersil, berorientasi pasar dan dikelola secara profesional, dengan skala ekonomi yang menguntungkan (Pertanian \& Perencanaan, 2004).

Berkembangnya permintaan pasar tanaman hias di Kota Makassar dalam beberapa tahun terakhir ini meningkat cukup tajam yang menyebabkan sektor produksi tanaman hias di Kota Makassar semakin aktif dan memandang hal tersebut sebagai peluang untuk memenuhi kebutuhan konsumen, hal ini tampak jelas dari tahun ke tahun trend penjualan tanaman hias di Kota Makassar meningkat setiap tahunnya seperti yang ditunjukkan pada gambar 1 berikut ini. 


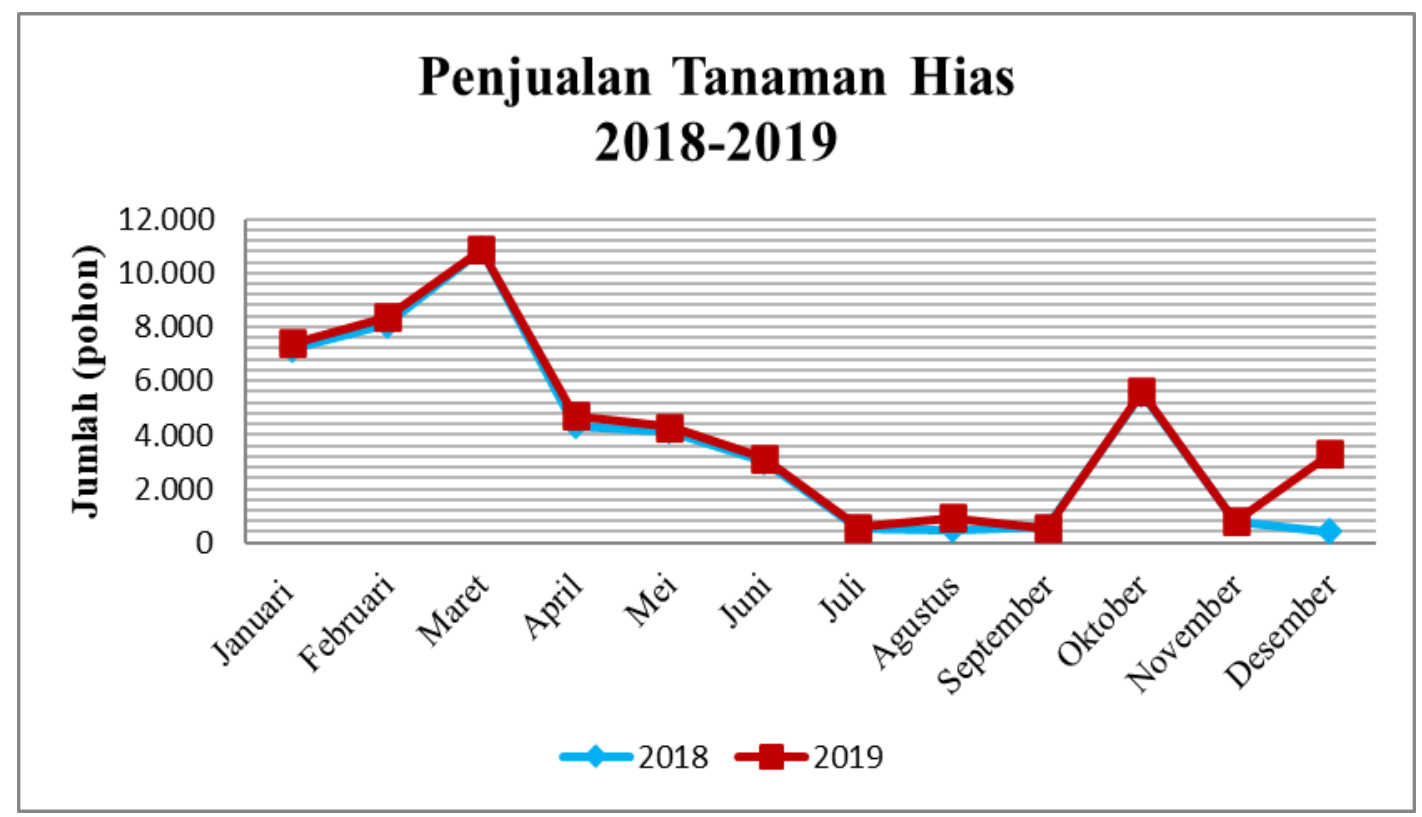

Gambar1. Grafik Trend Penjualan Tanaman Hias Tahun 2018-2019

Fakta saat ini, sebagian besar pelaku usaha tanaman hias di Kota Makassar tidak mengetahui positioning dari bisnis mereka sendiri, sehingga pelaku usaha tanaman hias tidak dapat melakukan perubahan, perbaikan, dan peningkatan pengelolaan/manajemen bisnis mereka dengan cepat dan tepat sehingga berakibat pada kekalahan persaingan serta kemajuan usaha tanaman hias di Kota Makassar menjadi semakin lambat. Studi penelitian terdahulu terkait penentuan positioning yang bergantung pada metode pemetaan persepsi hasilnya akan bersifat bias dan menimbulkan masalah yang berkaitan dengan validitas dan keandalan temuan (Green \& Carmone, 1969), (Hair Jr, 2006) Sedangkan studi kali ini akan menentukan positioning dengan menggunakan analisis CPM (Competitive Profile Matrix) yang mampu menyelidiki dan memetakan posisi perusahaan dalam beberapa kelompok perusahaan secara akurat.

Positioning adalah posisi perusahaan yang khas diantara pesaingnya yakni sejauhmana produsen berhasil memposisikan perusahaan, produk atau mereknya diantara pesaing lainnya. Positioning adalah bagian integral dari pemasaran (Kotler \& Armstrong, 2010), (Martos-Partal \& González-Benito, 2011) (Sirianni et al., 2013). Positioning, jika dilakukan dengan benar, maka akan mempengaruhi keunggulan kompetitif jangka panjang sebuah perusahaan (Hooley et al., 2001), (Kotler, 2003), (Porter, 1996). Hal ini juga dijelaskan oleh (Hassan \& Craft, 2012), (Kotler \& Armstrong, 2010) bahwa aktivitas penentuan positioning berdampak positif terhadap keunggulan kompetitif jangka panjang perusahaan. Strategi penentuan positioning yang sukses dikaitkan dengan kapabilitas utama perusahaan (Fuchs \& Diamantopoulos, 2010) sebab hal ini merupakan cara unik untuk memberikan nilai perusahaan kepada pelanggan (Blankson et al., 2018) (Keller et al., 2011).

Mempertimbangkan masalah diatas, maka perlu dilakukan penelitian tentang analisis positioning pelaku usaha tanaman hias di Kota Makassar. Tujuan penelitian ini 
adalah untuk mengidentifikasi karakteristik petani dan usahatani tanaman hias dan untuk menganalisis positioning setiap pelaku usaha tanaman hias di Kota Makassar.

\section{Metode Penelitian}

Penelitian ini menggunakan jenis penelitian deskriptif kuantitatif. Analisis deskriptif kuantitatif dalam penelitian ini digunakan untuk menganalisis karakteristik petani dan usahatani tanaman hias di Kota Makassar.

Sampel yang dijadikan obyek penelitian ini adalah petani/pelaku usaha tanaman hias di Kota Makassar. Jumlah populasi petani/pelaku usaha tanaman hias yang berada di Kota Makassar adalah sebanyak 182 orang. Metode pengambilan sampel pada penelitian ini yaitu dengan menggunakan teknik simple random sampling. Simple random sampling adalah teknik pengambilan sampel secara acak dimana setiap sampel diberi kesempatan yang sama untuk dipilih sebagai anggota sampel. Jumlah sampel yang digunakan dalam penelitian ini dihitung berdasarkan rumus rumus Taro Yamane sebagai berikut (Riduwan, 2013):

$$
\mathrm{n}=\frac{N}{\mathrm{~N} d^{2}+1}(1)
$$

Keterangan:

$\mathrm{n}=$ jumlah sampel

$\mathrm{N}=$ jumlah populasi (jumlah petani tanaman hias di Kota Makassar)

$\mathrm{d}^{2}=$ presisi (ditetapkan 20\% dengan tingkat kepercayaan $95 \%$ )

$$
\mathrm{n}=\frac{182}{1+\left(182 \times 0.2^{2}\right)}=21.98 \approx 30 \text { orang }
$$

Berdasarkan perhitungan diatas, maka petani yang dijadikan sampel dalam penelitian ini adalah sebanyak 30 orang yang tersebar dalam beberapa Kecamatan di Kota Makassar.

Data yang digunakan terdiri dari data primer dan data skunder. Data primer adalah data yang diperoleh secara langsung dari sumber data tanpa adanya perantara yaitu melalui hasil observasi, wawancara dan kuesioner.

Data sekunder adalah data yang diperoleh secara tidak langsung dari sumber data seperti melalui Dinas Pertanian dan Hortikultura Kota Makassar, Badan Pusat Statistik, bahan pustaka, dokumen, laporan hasil penelitian dan tulisan ilmiah yang menunjang penelitian ini.

Metode pengumpulan data yang digunakan menggunakan metode ovservasi dan wawancara. Observasi merupakan metode pengambilan data melalui proses pengamatan langsung di lapangan. Wawancara merupakan teknik pengumpulan data melalui proses dialog langsung kepada responden untuk mendapatkan informasi dan data yang diperlukan dalam penelitian. Bentuk wawancara dalam penelitian ini yaitu wawancara formal.

Analisis data dalam penelitian ini menggunakan deskriptif dan positioning. Analisis deskriptif merupakan analisis yang bertujuan untuk mengubah kumpulan data mentah menjadi bentuk yang mudah diuraikan dipahami dalam suatu tulisan ilmiah sehingga dapat menghasilkan sebuah kesimpulan. Untuk menjawab tujuan pertama dari 
penelitian ini ialah dengan menggunakan competitive profile matrix (CPM). Tabel competitive profile matrix (CPM) terdiri dari beberapa komponen yaitu faktor penentu keberhasilan (Critical Success Factors), peringkat (rating), bobot (Weighted), skor (Score), dan total skor (Total Score) yang di disajikan pada tabel 1. berikut ini.

Tabel 1 CPM (competitive profile matrix)

\begin{tabular}{|c|c|c|c|c|c|c|c|c|}
\hline \multirow{2}{*}{ No. } & \multirow{2}{*}{$\begin{array}{c}\text { Faktor } \\
\text { Penentu } \\
\text { Keberhasilan }\end{array}$} & \multirow{2}{*}{ Bobot } & \multicolumn{2}{|c|}{ Petani A } & \multicolumn{2}{|c|}{ Petani B } & \multicolumn{2}{|c|}{ Petani C } \\
\hline & & & Rating & Skor & Rating & Skor & Rating & Skor \\
\hline 1 & $\mathrm{~A}$ & & & & & & & \\
\hline 2 & B & & & & & & & \\
\hline 3 & $\mathrm{C}$ & & & & & & & \\
\hline & Total Skor & 1,00 & & & & & & \\
\hline
\end{tabular}

Sumber: (David, 2009)

\section{Hasil dan Pembahasan}

\section{A. Karakteristik Petani dan Usahatani Tanaman Hias}

\section{Karakteristik Petani/pelaku Usaha Tanaman Hias}

\section{a. Karakteristik Petani Tanaman Hias Berdasarkan Jenis Kelamin}

Karakteristik petani tanaman hias berdasarkan jenis kelamin terbagi atas dua yaitu laki-laki dan perempuan. Mayoritas petani tanaman hias di Kota Makassar sebagian besar adalah petani yang berjenis kelamin laki-laki dengan persentase sebesar $73 \%$ sedangkan petani yang berjenis kelamin perempuan hanya memiliki persentase sebesar 27\%. Data ini sejalan dengan hasil penelitian Virianita et al. (2019) yang menunjukkan bahwa petani yang berjenis kelamin laki-laki lebih dominan sebesar 65,7\% dibandingkan perempuan sebesar 34,3\% sehingga pelaku utama dalam kegiatan usaha tani masih didominasi oleh laki-laki. Sebaran petani tanaman hias berdasarkan jenis kelamin dapat dilihat pada Tabel 2.

Tabel 2 Sebaran petani tanaman hias berdasarkan jenis kelamin

\begin{tabular}{clcc}
\hline No. & \multicolumn{1}{c}{ Jenis Kelamin } & $\begin{array}{c}\text { Jumlah Petani } \\
\text { (Orang) }\end{array}$ & Persentase (\%) \\
\hline $\mathbf{1}$ & laki-laki & 22 & $73 \%$ \\
$\mathbf{2}$ & Perempuan & 8 & $27 \%$ \\
\hline \multicolumn{2}{c}{ Total } & 30 & $100 \%$ \\
\hline
\end{tabular}

Sumber: Data Primer, diolah (2020)

b. Karakteristik Petani Tanaman Hias Berdasarkan Usia

Usia setiap responden dalam penelitian ini terbagi atas lima kelompok yaitu 1) $\leq 20$ Tahun, 2) 21 - 30 Tahun, 3) 31 -40 Tahun, 4) $\geq 41$ Tahun. Petani tanaman hias yang berusia $\geq 41$ tahun memiliki persentase terbesar yaitu sebesar 53\%, sedangkan petani yang berusia 21 - 30 tahun dan $31-40$ tahun masing-masing memiliki persentase sebesar $20 \%$, dan usia $\leq 20$ tahun memiliki persentase sebesar 7\%. Data ini sejalan dengan hasil penelitian Virianita et al. (2019) yang menunjukkan bahwa sebagian besar petani 
berada dalam kategori usia tua $\geq 41$ Tahun. Sebaran petani tanaman hias berdasarkan usia dapat dilihat pada Tabel 3.

Tabel 3 Sebaran petani tanaman hias berdasarkan usia

\begin{tabular}{|c|c|c|c|}
\hline No. & Usia & $\begin{array}{c}\text { Jumlah Petani } \\
\text { (Orang) }\end{array}$ & Persentase (\%) \\
\hline 1 & $\leq 20$ Tahun & 2 & $7 \%$ \\
\hline 2 & $\overline{2} 1$ - 30 Tahun & 6 & $20 \%$ \\
\hline 3 & 31 - 40 Tahun & 6 & $20 \%$ \\
\hline 4 & $\geq 41$ Tahun & 16 & $53 \%$ \\
\hline & Total & 30 & $100 \%$ \\
\hline
\end{tabular}

Sumber: Data Primer, diolah (2020)

c. Karakteristik Petani Tanaman Hias Berdasarkan Jumlah Tanggungan Keluarga

Jumlah tanggungan keluarga setiap responden dalam penelitian ini terbagi atas lima kelompok yaitu 1) 3 Orang, 2) 4 Orang, 3) 5 Orang, 4) 6 Orang, dan 5) 7 Orang. Petani dengan jumlah tanggungan keluarga sebanyak 3 orang memiliki persentase tertinggi yaitu sebesar $39 \%$, adapun petani dengan jumlah tanggungan keluarga sebanyak 4 orang memiliki persentase sebesar 36\%, petani dengan jumlah tanggungan keluarga sebanyak 5 orang memiliki persentase sebesar $13 \%$, petani dengan jumlah tanggungan keluarga sebanyak 6 dan 7 orang masing-masing hanya memiliki persentase sebesar 7\%. Sedikitnya jumlah tanggungan keluarga pada sebagian besar petani tanaman hias di Kota Makassar diasumsikan bahwa pendapatan petani merupakan faktor pembatas utamanya. Menurut Ganis (2017) bahwa semakin banyak jumlah tanggungan keluarga maka semakin berat beban hidup yang dihadapi petani dan seharusnya diimbangi dengan semakin besar pendapatan yang diterima. Sebaran petani tanaman hias berdasarkan jumlah tanggungan keluarga dapat dilihat pada Tabel 4.

Tabel 4 Sebaran petani tanaman hias berdasarkan jumlah tanggungan keluarga

\begin{tabular}{cccc}
\hline No. & $\begin{array}{c}\text { Jumlah Tanggungan } \\
\text { Keluarga }\end{array}$ & $\begin{array}{c}\text { Jumlah Petani } \\
\text { (Orang) }\end{array}$ & Persentase (\%) \\
\hline $\mathbf{1}$ & 3 Orang & 12 & $40 \%$ \\
$\mathbf{2}$ & 4 Orang & 11 & $37 \%$ \\
$\mathbf{3}$ & 5 Orang & 4 & $13 \%$ \\
$\mathbf{4}$ & 6 Orang & 2 & $7 \%$ \\
$\mathbf{5}$ & 7 Orang & 2 & $7 \%$ \\
\hline \multicolumn{2}{c}{ Total } & 30 & $100 \%$ \\
\hline
\end{tabular}

Sumber: Data Primer, diolah (2020)

d. Karakteristik Petani Tanaman Hias Berdasarkan Tingkat Pendidikan

Tingkat pendidikan setiap responden dalam penelitian ini terbagi atas enam tingkat yaitu 1) SD, 2) SMP/sederajat, 3) SMA/sederajat, 4) Diploma, 5) S1, dan 6) S2/S3. Petani dengan tingkat pendidikan SMA memiliki persentase tertinggi yaitu sebesar $80 \%$, adapun petani dengan tingkat pendidikan SMP/sederajat memiliki persentase sebesar 13\%, dan 
petani dengan tingkat pendidikan S1 memiliki persentase sebesar $7 \%$. Menurut Gangsar (2008), tingkat Pendidikan merupakan sarana penting yang harus diperhatikan dalam hal meningkatkan produksi sumberdaya manusia. Pendidikan sangat mempengaruhi pola pikir, terutama dalam mengadopsi hal-hal yang diinformasikan, peran pendidikan tersebut juga dapat berpengaruh pada kemudahan dalam penerimaan ataupun penggunaan teknologi pertanian yang tersedia dan pengelolaan usahatani yang dilakukan, yang pada akhirnya secara tidak langsung berpengaruh pada peningkatan hasil produksi. Sebaran petani tanaman hias berdasarkan tingkat pendidikan dapat dilihat pada Tabel 5.

Tabel 5 Sebaran petani tanaman hias berdasarkan tingkat pendidikan

\begin{tabular}{clcc}
\hline No. & Tingkat Pendidikan & $\begin{array}{c}\text { Jumlah Petani } \\
\text { (Orang) }\end{array}$ & Persentase (\%) \\
\hline $\mathbf{1}$ & SD & 0 & $0 \%$ \\
$\mathbf{2}$ & SMP/sederajat & 4 & $13 \%$ \\
$\mathbf{3}$ & SMA/sederajat & 24 & $80 \%$ \\
$\mathbf{4}$ & Diploma & 0 & $0 \%$ \\
$\mathbf{5}$ & S1 & 2 & $7 \%$ \\
$\mathbf{6}$ & S2/S3 & 0 & $0 \%$ \\
\hline \multicolumn{2}{r}{ Total } & 30 & $100 \%$ \\
\hline
\end{tabular}

Sumber: Data Primer, diolah (2020)

e. Karakteristik Petani Tanaman Hias Berdasarkan Tingkat Pendapatan

Tingkat pendapatan setiap responden dalam penelitian ini terbagi atas empat kelompok yaitu 1) $\leq$ Rp. 3.000.000, 2) Rp. 4.000.000 - Rp. 15.000.000, 3) Rp. 16.000.000 - Rp. 25.000.000, dan 4) $\geq$ Rp. 25.000.000. Petani dengan tingkat pendapatan Rp. 4.000 .000 - Rp.15.000.000 memiliki persentase tertinggi yaitu sebesar $60 \%$, adapun petani dengan tingkat pendapatan $\leq$ Rp. 3.000.000 dan $\geq$ Rp. 25.000.000 masing-masing memiliki persentase sebesar $17 \%$, dan petani dengan tingkat pendapatan Rp. 16.000.000 - Rp.25.000.000 hanya memiliki persentase sebesar 6\%. Besarnya penghasilan usaha tani tidak hanya berguna untuk kelangsungan hidup rumah tangga tani, melainkan juga menjadi modal usaha yang memungkinkan keberlanjutan usaha tani. Hasil penelitian Virianita et al. (2019) menunjukkan bahwa sebanyak 96,6\% petani memperoleh penghasilan dari hasil usahatani mereka hanya $<8$ juta. Sebaran petani tanaman hias berdasarkan tingkat pendapatan dapat dilihat pada Tabel 6 .

Tabel 6 Sebaran petani tanaman hias berdasarkan tingkat pendapatan

\begin{tabular}{clcc}
\hline No. & \multicolumn{1}{c}{ Tingkat Pendapatan } & $\begin{array}{c}\text { Jumlah Petani } \\
\text { (Orang) }\end{array}$ & $\begin{array}{c}\text { Persentase } \\
(\mathbf{\%})\end{array}$ \\
\hline $\mathbf{1}$ & $\leq$ Rp. 3.000.000 & 5 & $17 \%$ \\
$\mathbf{2}$ & Rp. 4.000.000 - Rp. 15.000.000 & 18 & $60 \%$ \\
$\mathbf{3}$ & Rp. 16.000.000 - Rp. 25.000.000 & 2 & $7 \%$ \\
$\mathbf{4}$ & $\geq$ Rp. 25.000.000 & 5 & $17 \%$ \\
\hline \multicolumn{2}{c}{ Total } & 30 & $100 \%$ \\
\hline
\end{tabular}


Sumber: Data Primer, diolah (2020)

\section{B. Karakteristik Usahatani Tanaman Hias}

\section{Lokasi Usaha}

Lokasi usaha setiap responden dalam penelitian ini terbagi atas lima Kecamatan yaitu 1) Kecamatan Tamalate, 2) Rappocini, 3) Biringkanaya, 4) Panakukkang, dan 5) Tamalanrea. Lokasi usaha di Kecamatan Tamalate memiliki persentase jumlah petani terbanyak yaitu sebesar 43\%. Adapun Kecamatan Rappocini memiliki persentase sebesar 27\%, Kecamatan Panakukkang memiliki persentase sebesar 23\%, Kecamatan Biringkanaya dan Tamalanrea masing-masing hanya memiliki persentase sebesar 3\%. Kecamatan Tamalate merupakan Wilayah pusat pemasaran tanaman hias di Kota Makassar, sehingga jumlah petani tanaman hias di Wilayah tersebut lebih banyak dibanding yang berada di Kecamatan lainnya. Lokasi usaha merupakan salah satu strategi pemasaran yang cukup penting, sebab lokasi usaha dapat menentukan tingkat pendapatan suatu usaha. Menurut Sundari (2017), lokasi usaha yang strategis dapat menarik konsumen, sehingga pedagang dapat memaksimumkan penjualan dan labanya. Sebagaimana pendapat Wayan (2015) bahwa lokasi merupakan tempat usaha yang sangat mempengaruhi keinginan seorang konsumen untuk datang dan berbelanja. Sebaran petani tanaman hias berdasarkan lokasi usaha dapat dilihat pada Tabel 7.

Tabel 7 Sebaran petani tanaman hias berdasarkan lokasi usaha

\begin{tabular}{clcc}
\hline No. & Lokasi Usaha & $\begin{array}{c}\text { Jumlah Petani } \\
\text { (Orang) }\end{array}$ & Persentase (\%) \\
\hline $\mathbf{1}$ & Tamalate & 13 & $43 \%$ \\
$\mathbf{2}$ & Rappocini & 8 & $27 \%$ \\
$\mathbf{3}$ & Biringkanaya & 1 & $3 \%$ \\
$\mathbf{4}$ & Panakukkang & 7 & $23 \%$ \\
$\mathbf{5}$ & Tamalanrea & 1 & $3 \%$ \\
\hline & Total & 30 & $100 \%$ \\
\hline
\end{tabular}

Sumber: Data Primer, diolah (2020)

\section{Luas Lahan Usaha}

Luas lahan usaha setiap responden dalam penelitian ini terbagi atas empat luasan lahan yaitu 1) $\leq 5 \mathrm{~m}^{2}$, 2) $5-10 \mathrm{~m}^{2}$, 3) $10-15 \mathrm{~m}^{2}$, dan 4) $\geq 15$ $\mathrm{m}^{2}$. Luas lahan usaha $\geq 15 \mathrm{~m}^{2}$ memiliki persentase tertinggi yaitu sebesar $63 \%$, adapun luas lahan usaha $10-15 \mathrm{~m}^{2}$ memiliki persentase sebesar $27 \%$, luas lahan usaha $\leq 5 \mathrm{~m}^{2}$ memiliki persentase sebesar $7 \%$, dan luas lahan usaha 5-10 $\mathrm{m}^{2}$ hanya memiliki persentase sebesar $3 \%$. Sebagian besar petani tanaman hias di Kota Makassar memiliki luas lahan $\geq 15 \mathrm{~m}^{2}$, hal ini tentu berdampak positif terhadap usahatani mereka, sebab semakin luas lahan yang digunakan maka semakin besar peluang produksi dan pendapatan petani. Menurut Mubyarto (1989) luas lahan mempengaruhi petani dalam mengelola usahataninya. Luas kepemilikan lahan garapan berpengaruh terhadap petani dalam mengelola lahannya, dimana semakin luas lahan yang 
diusahakan maka semakin tinggi produksi dan pendapatan per kesatuan luasnya. Sebaran petani tanaman hias berdasarkan luas lahan usaha dapat dilihat pada Tabel 8.

Tabel 8 Sebaran petani tanaman hias berdasarkan luas lahan usaha

\begin{tabular}{cccc}
\hline No. & Luas Lahan Usaha & $\begin{array}{c}\text { Jumlah Petani } \\
\text { (Orang) }\end{array}$ & Persentase (\%) \\
\hline $\mathbf{1}$ & $\leq 5 \mathrm{~m}^{2}$ & 2 & $7 \%$ \\
$\mathbf{2}$ & $5-10 \mathrm{~m}^{2}$ & 1 & $3 \%$ \\
$\mathbf{3}$ & $10-15 \mathrm{~m}^{2}$ & 8 & $27 \%$ \\
$\mathbf{4}$ & $\geq 15 \mathrm{~m}^{2}$ & 19 & $63 \%$ \\
\hline & Total & 30 & $100 \%$ \\
\hline
\end{tabular}

Sumber: Data Primer, diolah (2020)

\section{Sumber Modal}

Sumber modal setiap responden dalam penelitian ini terbagi atas empat jenis sumber modal yaitu 1) modal pinjaman, 2) modal pinjaman dan patungan, 3) modal patungan, dan 4) modal sendiri. Modal sendiri memiliki persentase tertinggi yaitu sebesar $80 \%$, adapun modal pinjaman memiliki persentase sebesar $17 \%$, dan modal patungan hanya memiliki persentase sebesar $3 \%$. Sumber modal adalah salah satu faktor keberhasilan dalam melaksanakan kegiatan usahatani berkelanjutan (Virianita et al., 2019). Umumnya, sumber modal petani tanaman hias di Kota Makassar berasal dari modal sendiri, hal ini sejalan dengan hasil penelitian Iriyani dan Nugrahani (2016) yang menunjukkan bahwa modal usahatani yang selama ini petani pergunakan sebagian besar (82\%) adalah modal sendiri, sedangkan $18 \%$ lainnya berhasil memperoleh bantuan modal dari Kelompok Tani (Poktan). Sebaran petani tanaman hias berdasarkan sumber modal dapat dilihat pada Tabel 9.

Tabel 9 Sebaran petani tanaman hias berdasarkan sumber modal

\begin{tabular}{|c|c|c|c|}
\hline No. & Sumber Modal & $\begin{array}{c}\text { Jumlah Petani } \\
\text { (Orang) }\end{array}$ & Persentase (\%) \\
\hline $\mathbf{1}$ & \multirow{2}{*}{$\begin{array}{l}\text { Modal pinjaman } \\
\text { Modal pinjaman dan } \\
\text { patungan }\end{array}$} & 5 & $17 \%$ \\
\hline 2 & & 0 & $0 \%$ \\
\hline 3 & \multirow{2}{*}{$\begin{array}{l}\text { Modal patungan } \\
\text { Modal sendiri }\end{array}$} & 1 & $3 \%$ \\
\hline 4 & & 24 & $80 \%$ \\
\hline & Total & 30 & $100 \%$ \\
\hline
\end{tabular}

Sumber: Data Primer, diolah (2020)

\section{Skala Pasar}

Skala pasar setiap responden dalam penelitian ini terbagi atas empat skala yaitu 1) lokal, 2) lokal dan nasional, 3) nasional dan internasional, dan 4) lokal, nasional dan Internasional. Skala pasar lokal memiliki persentase tertinggi yaitu sebesar $70 \%$, adapun skala pasar lokal dan nasional hanya memiliki persentase sebesar 30\%. Sebagian besar petani tanaman hias hanya mampu memasarkan hasil produksi mereka dalam lingkup lokal. Menurut 
Illiyyun (2012), pasar lokal adalah pasar yang daerah pemasarannya hanya meliputi daerah tertentu dan pada umumnya hanya menawarkan barang yang dibutuhkan oleh masyarakat di sekitarnya. Sebaran petani tanaman hias berdasarkan skala pasar dapat dilihat pada Tabel 10.

Tabel 10 Sebaran petani tanaman hias berdasarkan skala pasar

\begin{tabular}{|c|c|c|c|}
\hline No. & Skala Pasar & $\begin{array}{c}\text { Jumlah Petani } \\
\text { (Orang) }\end{array}$ & Persentase (\%) \\
\hline $\mathbf{1}$ & Lokal & 21 & $70 \%$ \\
\hline 2 & Lokal dan Nasional & 9 & $30 \%$ \\
\hline 3 & Nasional dan Internasional & 0 & $0 \%$ \\
\hline 4 & $\begin{array}{l}\text { Lokal, Nasional dan } \\
\text { Internasional }\end{array}$ & 0 & $0 \%$ \\
\hline & Total & 30 & $100 \%$ \\
\hline
\end{tabular}

Sumber: Data Primer, diolah (2020)

\section{Status Kepemilikan Usaha}

Status kepemilikan usaha setiap responden dalam penelitian ini terbagi atas empat status yaitu 1) milik keluarga, 2) sewa, 3), bagi hasil, dan 4) milik sendiri. Status usaha milik sendiri memiliki persentase tertinggi yaitu sebesar $90 \%$, adapun status usaha bagi hasil hanya memiliki persentase sebesar $10 \%$. Pada umumnya, status kepemilikan usaha setiap petani tanaman hias di Kota Makassar adalah milik sendiri. Status kepemilikan usaha milik sendiri memungkinkan pemiliknya untuk bebas mengelola usaha tanpa campur tangan pihak lain (Ganis, 2017). Sebaran petani tanaman hias berdasarkan status kepemilikan lahan dapat dilihat pada Tabel 11.

Tabel 11 Sebaran petani tanaman hias berdasarkan status kepemilikan usaha

\begin{tabular}{clcc}
\hline No. & Status Kepemilikan Usaha & $\begin{array}{c}\text { Jumlah Petani } \\
\text { (Orang) }\end{array}$ & Persentase (\%) \\
\hline $\mathbf{1}$ & Milik keluarga & 0 & $0 \%$ \\
$\mathbf{2}$ & Sewa & 0 & $0 \%$ \\
$\mathbf{3}$ & Bagi hasil & 3 & $10 \%$ \\
$\mathbf{4}$ & Milik sendiri & 27 & $90 \%$ \\
\hline & Total & 30 & $100 \%$
\end{tabular}

Sumber: Data Primer, diolah (2020)

\section{Analisis Competitive Profile Matrix (CPM)}

Berdasarkan hasil analisis Competitive Profile Matrix (CPM) yang dibantu dengan komponen pendukung lainnya seperti faktor penentu keberhasilan, bobot, rating, skor, dan total skor maka dihasilkan peringkat positioning setiap petani/pelaku usaha tanaman hias di Kota Makassar seperti yang disajikan pada tabel 12 berikut. 
Riska Tiasmalomo, Didi Rukmana dan Mahyuddin

Tabel 12 Peringkat positioning setiap petani/pelaku usaha tanaman hias

\begin{tabular}{|c|c|c|}
\hline Responden & Nilai Positioning & Peringkat Positioning \\
\hline 1 & 3,00 & 16 \\
\hline 2 & 2,88 & 21 \\
\hline 3 & 3,03 & 15 \\
\hline 4 & 2,96 & 17 \\
\hline 5 & 2,75 & 25 \\
\hline 6 & 3,52 & 4 \\
\hline 7 & 3,62 & 3 \\
\hline 8 & 3,68 & 2 \\
\hline 9 & 3,25 & 9 \\
\hline 10 & 1,62 & 30 \\
\hline 11 & 3,18 & 11 \\
\hline 12 & 2,51 & 27 \\
\hline 13 & 2,30 & 28 \\
\hline 14 & 2,58 & 26 \\
\hline 15 & 1,93 & 29 \\
\hline 16 & 2,75 & 24 \\
\hline 17 & 3,37 & 5 \\
\hline 18 & 3,77 & 1 \\
\hline 19 & 3,03 & 14 \\
\hline 20 & 2,78 & 23 \\
\hline 21 & 3,32 & 7 \\
\hline 22 & 2,78 & 22 \\
\hline 23 & 2,96 & 18 \\
\hline 24 & 3,12 & 13 \\
\hline 25 & 2,91 & 20 \\
\hline 26 & 2,96 & 19 \\
\hline 27 & 3,28 & 8 \\
\hline 28 & 3,22 & 10 \\
\hline 29 & 3,18 & 12 \\
\hline 30 & 3,37 & 6 \\
\hline
\end{tabular}

Sumber: Data Primer, diolah (2020)

Berdasarkan diatas yang menunjukkan bahwa nilai positioning tertinggi berturut-turut dikuasai oleh responden 18 (Yetty) dengan nilai positioning sebesar 3,769; responden 8 (Arianto) dengan nilai positioning sebesar 3,678; dan responden 7 (Sultan) dengan nilai positioning sebesar 3,621. Dalam dunia usaha, pengetahuan tentang posisi perusahaan adalah penting (Firdaus, 2011). Adapun yang menjadi faktor unggul keberhasilan usaha ketiga petani/pelaku usaha tersebut ialah status lahan usaha dengan perolehan skor sebesar 0,296; pertumbuhan usaha dengan perolehan skor sebesar 0,292; dan tingkat keuntungan dengan perolehan skor sebesar 0,288. Ketiga faktor unggul tersebut menjadi kekuatan internal bagi ketiga petani/pelaku usaha tersebut sehingga memiliki positioning yang lebih unggul dibanding petani/pelaku usaha lainnya. Menurut (David, 2009) competitive profile matrix adalah matriks yang mengidentifikasi pesaing-pesaing utama suatu perusahaan serta kekuatan dan 
kelemahan khusus sebuah perusahaan. Sehingga analisis competitive profile matrix ini dapat membantu seorang pelaku usaha melihat keunggulan maupun kelemahan tiap -tiap pelaku usaha lainnya. Khusus bagi perusahaan berskala kecil dan menengah, Competitive profile matrix merupakan alat analisis strategi pemasaran yang efektif dan efisien. Keefektifan dan keefisienan tersebut dapat diketahui dengan melihat perbandingan nilai setiap faktor penentu keberhasilan (Harisudin, 2011). Faktor penentu keberhasilan pada competitive profile matrix mencakup beberapa masalah internal maupun eksternal pada sebuah perusahaan.

\section{Kesimpulan}

Karakteristik umum petani tanaman hias di Kota Makassar adalah berjenis kelamin laki-laki, berusia $\geq 41$ Tahun, jumlah tanggungan keluarga sebanyak 3 orang, tingkat pendidikan SMA, dan tingkat pendapatan Rp. 4.000.000 - Rp.15.000.000. Sedangkan karakteristik umum usahatani tanaman hias di Kota Makassar adalah lokasi usaha sebagian besar berada di Kecamatan Tamalate, luas lahan usaha $\geq 15 \mathrm{~m}^{2}$, sumber modal usaha dari modal sendiri, skala pasar hanya sebatas wilayah lokal, dan status kepemilikan usaha adalah milik sendiri. Nilai positioning tertinggi berturut-turut dikuasai oleh responden 18 (Yetty) dengan nilai positioning sebesar 3,769; responden 8 (Arianto) dengan nilai positioning sebesar 3,678; dan responden 7 (Sultan) dengan nilai positioning sebesar 3,621. 


\section{BIBLIOGRAFI}

Blankson, C., Nkrumah, M. F., Opare, G., \& Ketron, S. (2018). Positioning strategies and congruence in the positioning of high-end indigenous and foreign retailers in sub-Saharan Africa: An illustration from Ghana. Thunderbird International Business Review, 60(4), 535-548.

Çelik, Y., \& Arisoy, H. (2013). Competitive analysis of outdoor ornamental plants sector: a case study of Konya province, Turkey. Journal of Horticultural Research, 21(2), 5-16.

Meisintya De Nanda, R. F. B. (2019). Uji Waktu Alir dan Uji Kompresibilitas Granul Pati Kentang dengan Metode Granulasi Basah. Syntax, 1(5), 59.

David, F. R. (2009). Strategic Management: Manajemen Strategis Konsep. Jakarta [ID]. Penerbit Salemba Empat.

Fuchs, C., \& Diamantopoulos, A. (2010). Evaluating the effectiveness of brand-positioning strategies from a consumer perspective. European Journal of Marketing.

Ganis, G.S. 2017. Analisis Pendapatan dan Keberlanjutan Usaha Pertanian Carica (Carica pubescens) di Kecamatan Kejajar, Kabupaten Wonosobo. Skripsi. Departemen Ekonomi Sumberdaya dan Lingkungan, Fakultas Ekonomi dan Manajemen, Institut Pertanian Bogor. Bogor.

Gangsar, W.S. dan T. Wijayant.2008. Peranan Prima Tani terhadapa Pendapatan Petani Padi Sawah di Desa Suliliran Baru Kecamatan Pasit Belengkong Kabupaten Paser. J-SEP 2(1): 23-29.

Green, P. E., \& Carmone, F. J. (1969). Multidimensional scaling: An introduction and comparison of nonmetric unfolding techniques. Journal of Marketing Research, $6(3), 330-341$.

Hair Jr, J. F. (2006). Black, Wc, Babin, Bj Anderson, Re \& Tatham, Rl (2006). Multivariate Data Analysis, 6.

Harisudin, M. (2011). Competitive profile matrix sebagai alat analisis strategi pemasaran produk atau jasa. Jurnal Sepa, 7(2), 80-84.

Hassan, S. S., \& Craft, S. (2012). Examining world market segmentation and brand positioning strategies. Journal of Consumer Marketing.

Hooley, G., Greenley, G., Fahy, J., \& Cadogan, J. (2001). Market-focused resources, competitive positioning and firm performance. Journal of Marketing Management, 17(5-6), 503-520.

Illiyyun. 2012. Revitalisasi pasar tradisional di Babat Kabupaten Lamongan. 
Undergraduate thesis. Malang: Universitas Islam Negeri Maulana Malik Ibrahim.

Iriyani, D. dan P. Nugrahani. 2016. Karakterisasi Faktor Sosial Ekonomi Berdasarkan Analisis Komponen Principal pada Pertanian Periurban Kota Surabaya. Jurnal Ilmiah Rekayasa 9(1): 18-43.

Keller, K. L., Parameswaran, M. G., \& Jacob, I. (2011). Strategic brand management: Building, measuring, and managing brand equity. Pearson Education India.

Kotler, P. (2003). Marketing for Hospitality and Tourism, 5/e. Pearson Education India.

Kotler, P., \& Armstrong, G. (2010). Principles of marketing. Pearson education.

Martos-Partal, M., \& González-Benito, Ó. (2011). Store brand and store loyalty: The moderating role of store brand positioning. Marketing Letters, 22(3), 297-313.

Mubyarto. 1989. Pengantar Ekonomi Pertanian. LP3ES. Jakarta.

Pertanian, D., \& Perencanaan, B. (2004). Statistik pertanian... Biro tsb.

Porter, M. E. (1996). What is strategy? Harvard Business Review, 74(6), 61-78.

Riduwan. 2013. Metode dan Teknik Menyusun Tesis. Bandung : Alfabeta.

Shinta, A. L. F. (2019). Pengelolaan Resort Pattunuang Karaenta dalam Perspektif Etnoekologi di Kabupaten Maros. LaGeografia, 16(3), 137-143.

Sirianni, N. J., Bitner, M. J., Brown, S. W., \& Mandel, N. (2013). Branded service encounters: Strategically aligning employee behavior with the brand positioning. Journal of Marketing, 77(6), 108-123.

Sundari. 2017. Pengaruh Lokasi Usaha dan Jam Kerja Terhadap Tingkat Pendapatan Pedagang dalam Perspektif Ekonomi Islam. Skripsi. Fakultas Ekonomi dan Bisnis Islam, Universitas Islam Negeri Raden Intan Lampung. Lampung.

Umar, H. (2013). Metode penelitian untuk skripsi dan tesis. Jakarta: Rajawali.

Virianita, R., T. Soedewo, S. Amanah, dan A. Fatchiya. 2019. Persepsi Petani terhadap Dukungan Pemerintah dalam Penerapan Sistem Pertanian Berkelanjutan. Jurnal Ilmu Pertanian Indonesia (JIPI) 24 (2): 168-177.

Wayan, I.S. 2015. Analisis Faktor-faktor yang Mempengaruhi Pemilihan Lokasi Usaha Pedagang Kaki Lima di Pantai Penimbangan Kecamatan Buleleng, Kabupaten Buleleng. Jurnal Pendidikan Ekonomi Undhiksha 5(1). 